\title{
EXPERIMENTAL STUDY ON BOTTOM TOPOGRAPHY CHANGE IN HARBOR DUE TO TSUNAMI
}

\author{
Tsutomu Sakakiyama ${ }^{1}$, Masafumi Matsuyama ${ }^{1}$ and Takumi Yoshii
}

\begin{abstract}
Bottom topography change due to tsunami was experimentally investigated using a rectangular harbor model in a 2-D wave flume. Water surface level and velocity field were obtained as well to discuss the external forces. Accumulation region was observed in the middle of the harbor inside. Formed was conical bed topography. Erosion was around the accumulated region and at the breakwater head as local scour. These topography changes were caused by the tsunami-induced vortices inside the harbor and at the breakwater head.
\end{abstract}

Keywords: tsunami; sand transport; topography change; vortex; water elevation level; velocity field

\section{INTRODUCTION}

The Indian Ocean tsunami in 2004 has revealed that the tsunamis caused several severe problems on sand movement. So far studies on the sand movement on tsunami were carried out mainly to apply a numerical simulation (Tahahashi, et al., 2000) and to investigate sand transport rate (Fuji et al., 1993, Yoshii, et al., 2009; Yoshii, et al., 2010).

In Japan, nuclear power plants were constructed in coastal areas. One of the main purposes is to take in cooling water from sea. Inlets for cooling water were usually constructed in a harbor of a nuclear power plant. A certain amount of cooling water should be taken in to shut down a nuclear reactor when tsunami attacks. Therefore, it is of great concern whether or not the sand movement due to tsunami causes closure of the inlet for cooling water. To secure the stability of nuclear power plants, the method to estimate the tsunami height has been established (The Tsunami Evaluation Subcommittee, JSCE, 2002). However, its assessment method does not include a method to evaluate the topography change in a harbor due to tsunami and therefore, it is required to establish the method on the bed topography change.

The present paper described the bottom topography change in a harbor due to tsunami. Basic experiments were carried out to investigate the bottom topography change and the flow inside a harbor due to tsunami to understand the phenomena and to obtain dataset to verify a numerical simulation model.

\section{EXPERIMENTAL METHOD}

Experiments were carried out using a two dimensional wave flume as shown in Fig. 1 (78m long, $0.9 \mathrm{~m}$ wide and $1.2 \mathrm{~m}$ deep). A model of flat seabed was constructed connecting with a flat bottom of the wave channel through a $1 / 10$ uniform slope. The sand bed of $5 \mathrm{~m}$ long, $0.9 \mathrm{~m}$ wide and $0.10 \mathrm{~m}$ deep was placed on the flat seabed. The water depth in front of a wave board is $0.735 \mathrm{~m}$ and that on the sand bed $0.075 \mathrm{~m}$. Wave gages were installed at five locations denoted with $\mathrm{H} 1$ through $\mathrm{H} 5$ outside the harbor model.

A model of rectangular harbor was constructed on the sand bed in the wave flume as shown in Fig.2. The harbor model is $150 \mathrm{~cm}$ long and $90 \mathrm{~cm}$ wide and the harbor entrance is $24 \mathrm{~cm}$ wide. The breakwater is $66 \mathrm{~cm}$ long, $12 \mathrm{~cm}$ wide and is enough high not to cause wave overtopping.

Free surface displacement, velocity and turbidity were measured at five locations from point 6 thorough 10 as shown in Fig.2. A notion of H6 means the wave gage at point 6 and U6 the horizontal component of velocity in the $x$-direction, V6 that in the $y$-direction and $\mathrm{C} 6$ the turbidimeter. At the harbor entrance denoted with the point 7 , the turbidity was not measured because the sensor was not installed not to disturb the flow through the narrow harbor entrance.

Sand bed topography was measured both at the initial and final stages. The experiments were conducted with the absorption of the reflected wave to investigate reproduction of the bottom topography change. Another case was carried out without the absorption of the reflected wave. The intervals of the measurement of the topography were $\Delta x=4 \mathrm{~cm}$ in the $x$-direction and $\Delta y=1 \mathrm{~cm}$ in the $y$-direction. Three CCD

\footnotetext{
${ }^{1}$ Central Research Institute of Electric Power Industry, 1646 Abiko, Abiko-city, Chiba 270-1194, Japan
} 


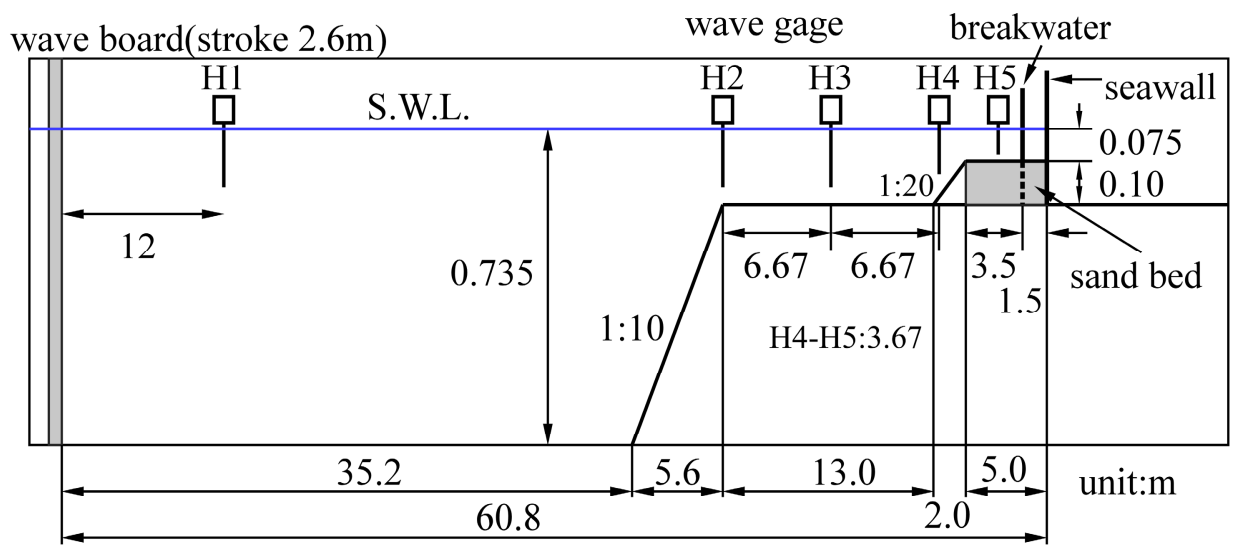

Figure 1. Experimental setup (2 dimensional wave flume, $78 \mathrm{~m}$ long, $0.9 \mathrm{~m}$ wide and $1.2 \mathrm{~m}$ deep).

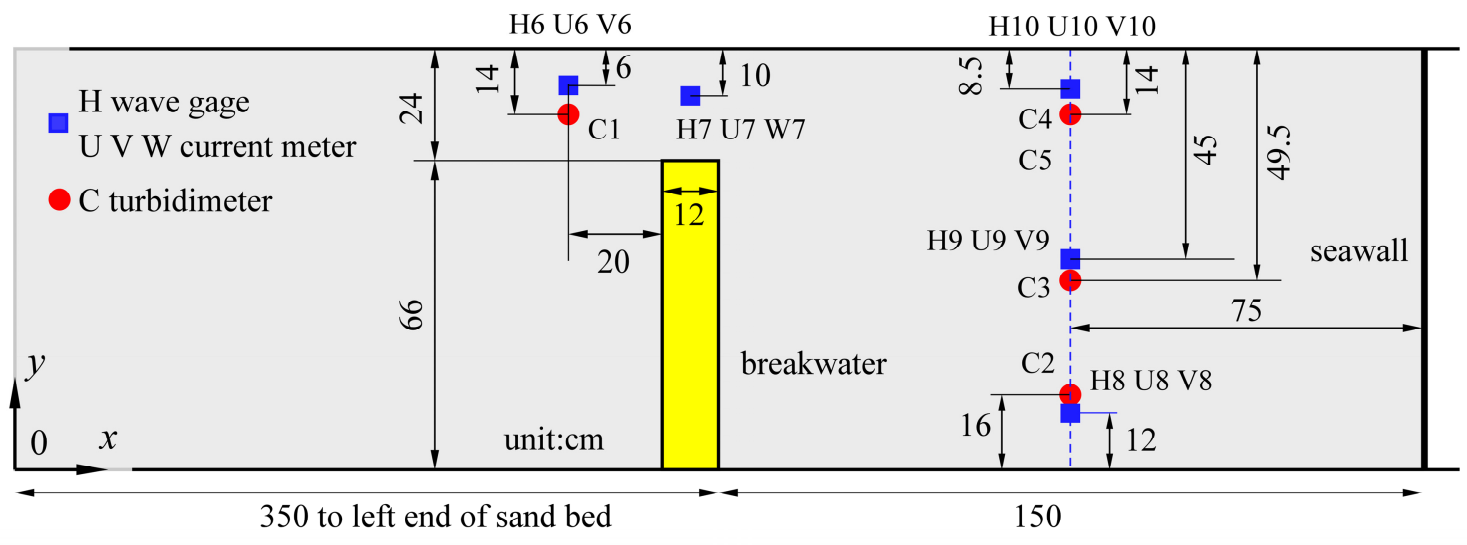

Figure 2. Plane view of sand bed, harbor model and locations of wave gages, current meters and turbidimeter.

Laser displacement meters were used to measure the bed topography. The resolution of the depth meter was $\Delta z=0.01 \mathrm{~cm}$.

In addition to the experiments of the topography change of the sand bed, measured were the water surface level and two horizontal components of the velocity both inside and outside the harbor. For this purpose, the seabed was changed to the fixed bed made of cement mortar. Arrays of wave gages and current meters were used. The intervals of measurement were $6 \mathrm{~cm}$ in both $x$ - and $y$-directions. Measurements were repeated by moving the arrays to cover the whole harbor area. After the measurements, all data were synchronized using one reference signal of the free surface displacement $\mathrm{H} 1$. Velocity field and contour of water surface elevation were obtained. A sampling frequency was $100 \mathrm{~Hz}$.

One of the purposes of the present experiments is to obtain the data on the bottom topography change due to a single tsunami train. That makes conditions simpler when verifying a numerical simulation model with the experimental data. Figure. 3 shows the time history of the water surface elevation at the wave generator. A single crested tsunami like a solitary wave was generated from $t=0$ to $t=50 \mathrm{~s}$. In the wave flume, the reflected waves were generated from the $1 / 10$ bottom slope connecting two flat beds and from the breakwater. In Fig.3, the negative wave surface elevation follows to absorb the reflected wave from the wave board to the sand bed. This negative part of the signal was obtained by resolving the waves into the incident and reflected waves applying the method by Mizuguchi (1991) using the free water displacement and horizontal component of velocity at the location $\mathrm{H1}$.

Figure.4 (a) shows the comparison of free surface displacement with no wave-absorption and with the wave-absorption at the wave gage $\mathrm{H} 1$ in the uniform water depth. The time histories from $t=100 \mathrm{~s}$ to $125 \mathrm{~s}$ are a reflected waves from the 1/10-slope connecting the flat bottom and the flat bed. The dotted line shows the free surface displacement including the re-reflected wave from the wave board. The comparison 


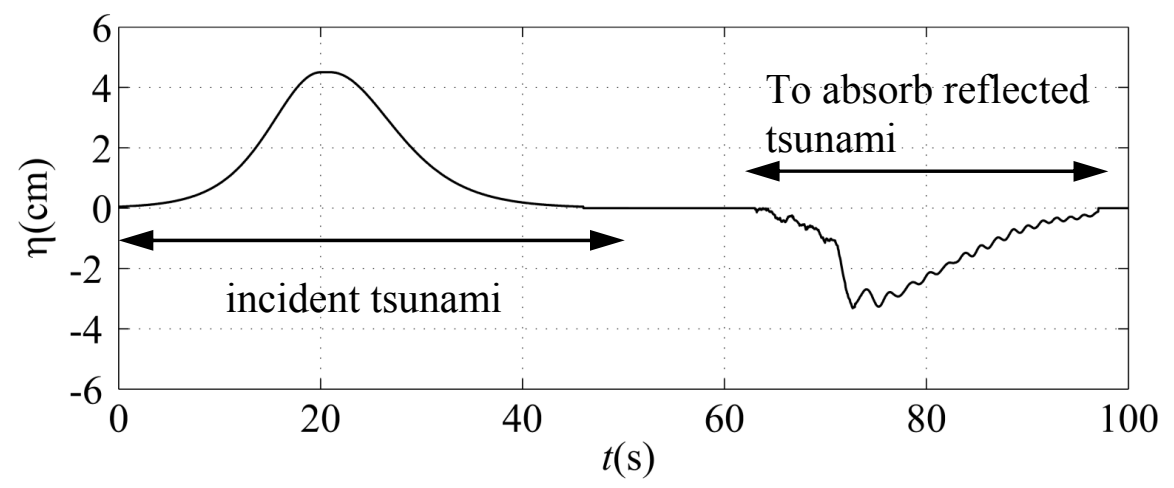

Figure 3. Time histories of signal for water surface elevation at wave board with both incident and absorbing reflected waves

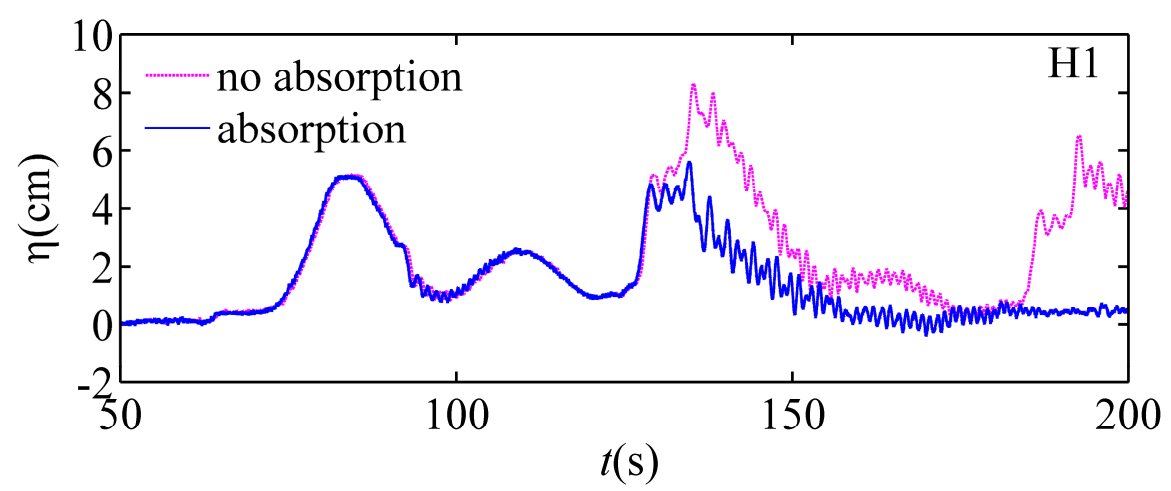

(a) Time histories of water surface elevation in the uniform water depth of $0.735 \mathrm{~m}$ at location $\mathrm{H} 1$.

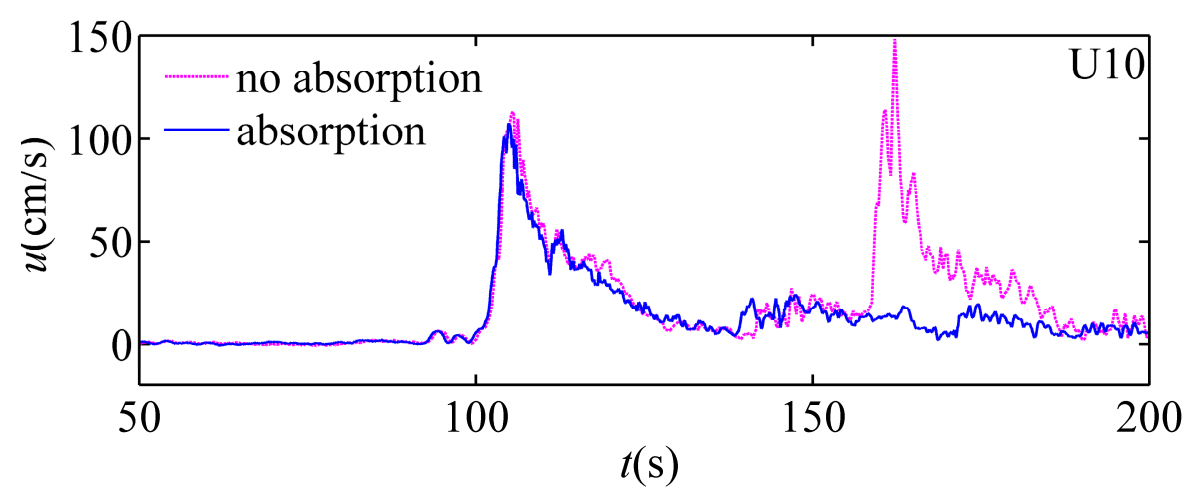

(b) Time histories of horizontal component of velocity inside harbor model at location U10.

Figure 4. Time histories of water surface elevation and horizontal component of velocity showing effectiveness of reflected wave absorbing.

of the time histories after $t=125 \mathrm{~s}$ shows that the reflected wave from the breakwater was absorbed effectively. Figure 4 (b) shows the time history of horizontal component of velocity of U10 measured inside the harbor. With the reflected wave absorption, a single tsunami train arrived and after 140s the velocity is less than about $30 \mathrm{~cm} / \mathrm{s}$, which is lower than the velocity of the incipient sand movement. 


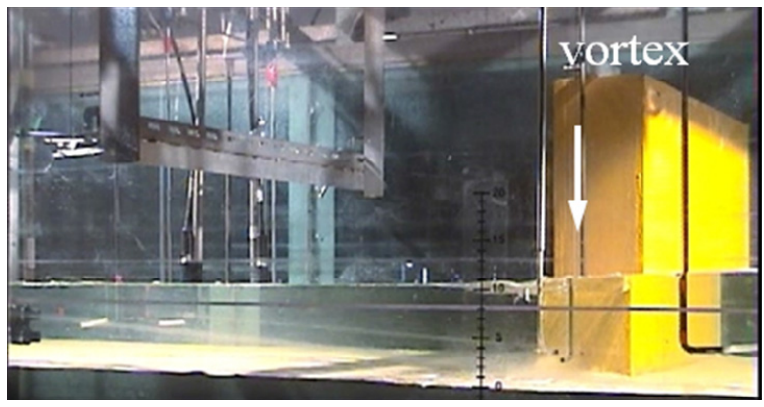

(a) Vortex generating at breakwater head

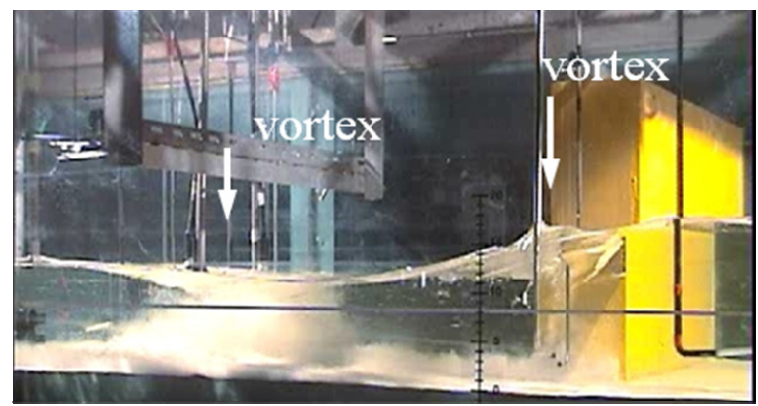

(c) A vortex growing inside harbor

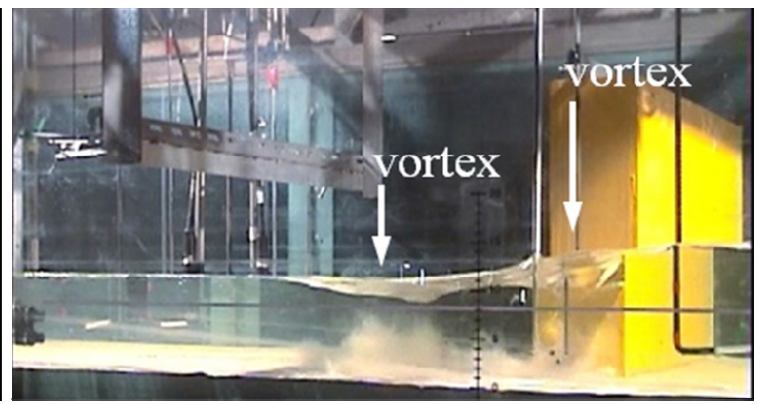

(b) A vortex moving into harbor and one staying at breakwater head

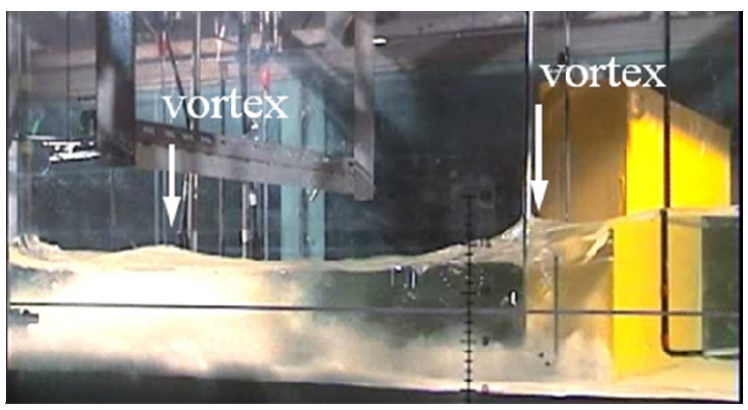

(d) Vortex inside harbor entraining suspended sand

Figure 5. Vortices at breakwater head and inside harbor (tsunami propagates from right to left)

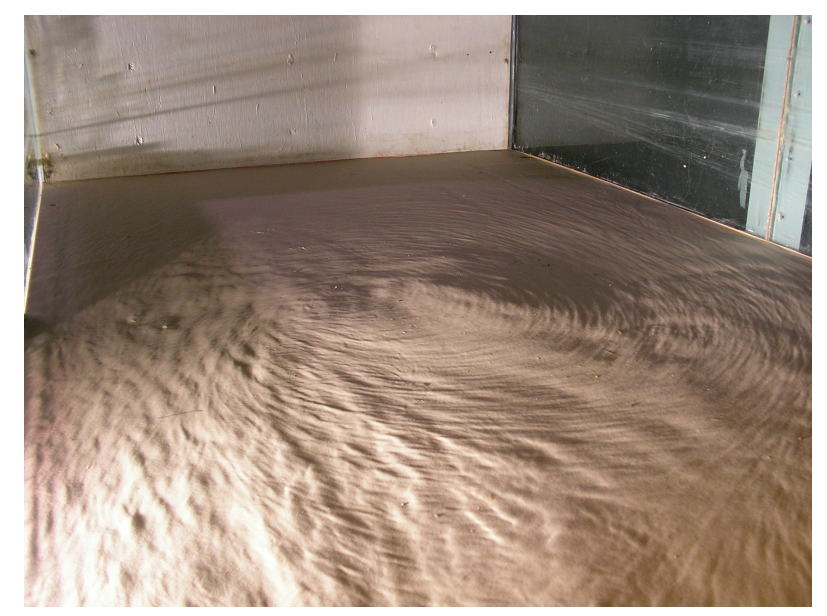

Figure 6. Conical bottom topography inside harbor model generated by tsunami

\section{EXPERIMENTAL RESULTS}

\section{Topography change}

Figure. 5 shows a process of generating vortices in the harbor due to the tsunami. At first, a vortex was generated at the breakwater head when the tsunami arrived at the breakwater (Fig.5 (a)). As the water surface level of the tsunami increased, the vortex separated from the breakwater head and it moved into the inside of the harbor while the original vortex still kept staying at the original position (Fig.5 (b)). The moving vortex produced suspended load with high concentration (Fig.5 (c)). The first vortex remaining at the head of the breakwater produced local scour (Fig.5 (d)). Figure.6 features the bottom topography inside the harbor model. This photo was taken from the harbor entrance. It shows the conical form with its 


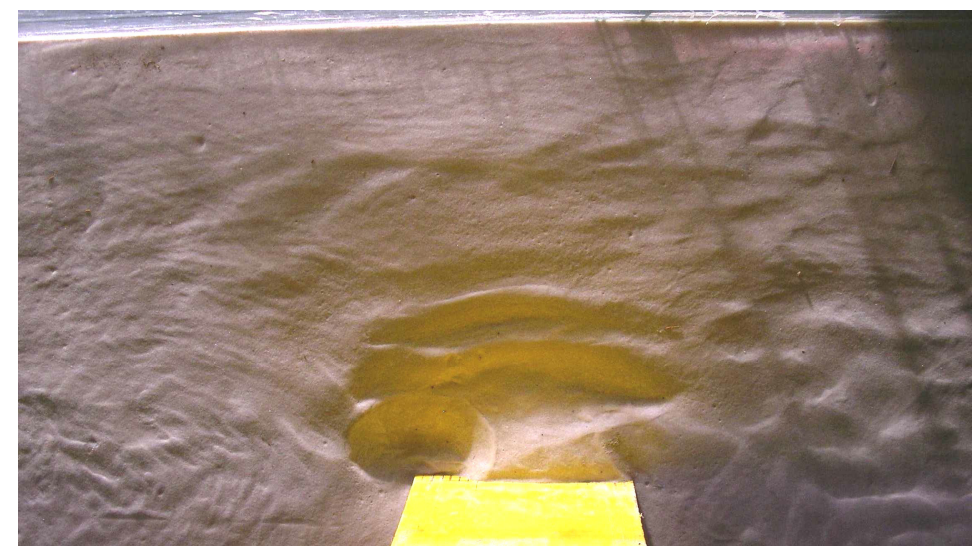

(a) Photograph of local scour

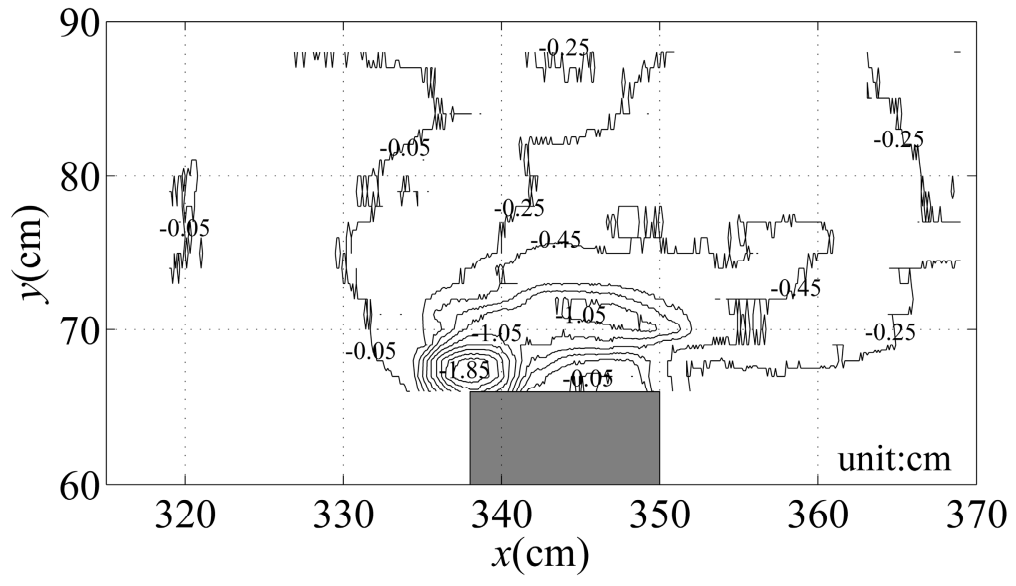

(b) Measured with resolutions of $\Delta x=0.1 \mathrm{~cm}, \Delta y=1 \mathrm{~cm}$ and $\Delta z=0.01 \mathrm{~cm}$

Figure 7. Local sour at head of breakwater (left: outside of harbor and right: inside harbor)

top being located near the center of harbor. It is also observed that paths along the streamlines of the vortex. The maximum height of the conical form is $0.7 \mathrm{~cm}$.

As the photos on the vortices generation shown in Fig.5, one of two vortices stayed at the breakwater head. This vortex caused the local scour at the breakwater head. Fig.7 (a) shows the resultant local scour. In this particular area, the topography was measured at every $1 \mathrm{~cm}$ in the $y$-direction while it was measured at every $0.1 \mathrm{~cm}$ in the $x$-direction. The topography change is shown in Fig. 7(b). The maximum depth eroded was about $1.5 \mathrm{~cm}$. The volume eroded in this is about $150 \mathrm{~cm}^{3}$ and no deposition was observed.

The bottom topography change in a whole area was shown in Fig.8. While the significant erosion is observed in the area near the breakwater head in the harbor entrance, the deposition is around the center of the harbor. Erosion areas are confirmed around the conically deposited area. At three corners of the harbor slight deposition areas are observed. Fig.9 shows the profile of the topography change at $x=420 \mathrm{~cm}$ along the $y$-axis. Fig. 10 shows that of the topography change at $y=44 \mathrm{~cm}$ along the $x$-axis. Both figures show the featuring profile. The erosion depth observed along the $y$-direction is deeper than that observed along the $x$-direction. Fig. 10 also shows the deposition in front of the breakwater outside the harbor between $x=320$ and $340 \mathrm{~cm}$.

Table. 1 shows the budged of volume of topography change. Ratios normalized with the volume of region 1 are also shown in this table. Region1 of the harbor entrance is defined as the region where measurement was done shown as in Fig.7 (b) giving the eroded volume of local scour. Region 2 of the harbor inside is defined as the area from the breakwater wall at $x=350 \mathrm{~m}$ up to the seawall $x=500 \mathrm{~m}$. So strictly speaking, these areas are slightly overlapped. Although the local sour at the breakwater head is a 


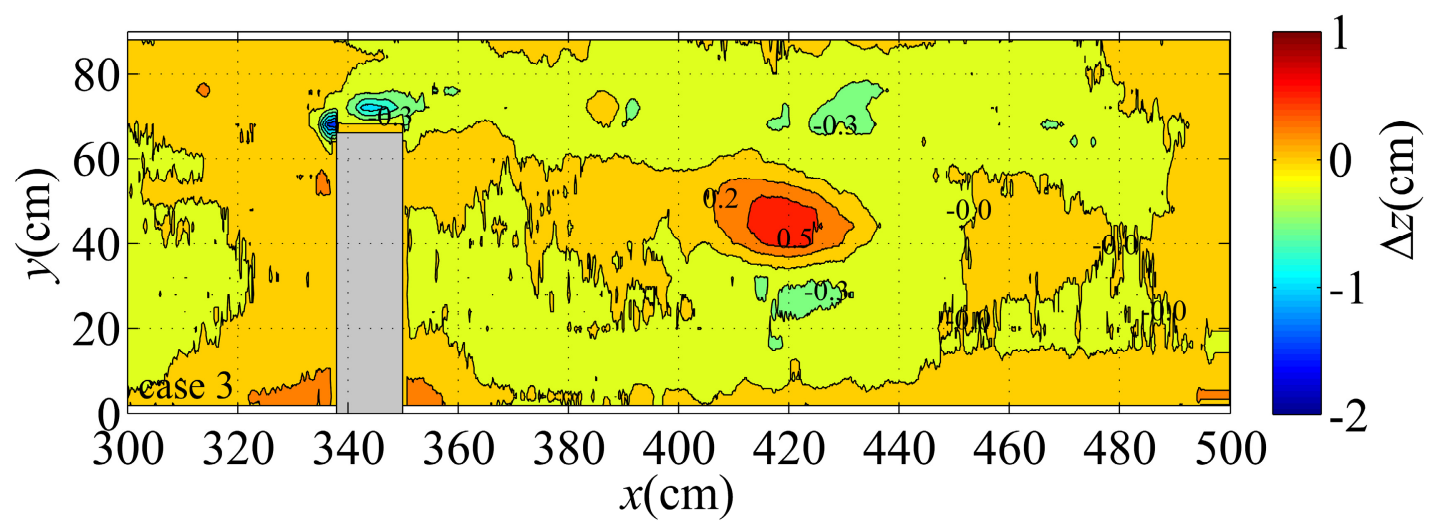

Figure 8. Bottom topography change featuring deposition near the center of harbor and local scour at head of breakwater measured with resolutions of $\Delta x=0.1 \mathrm{~cm}, \Delta y=4 \mathrm{~cm}$ and $\Delta z=0.01 \mathrm{~cm}$.

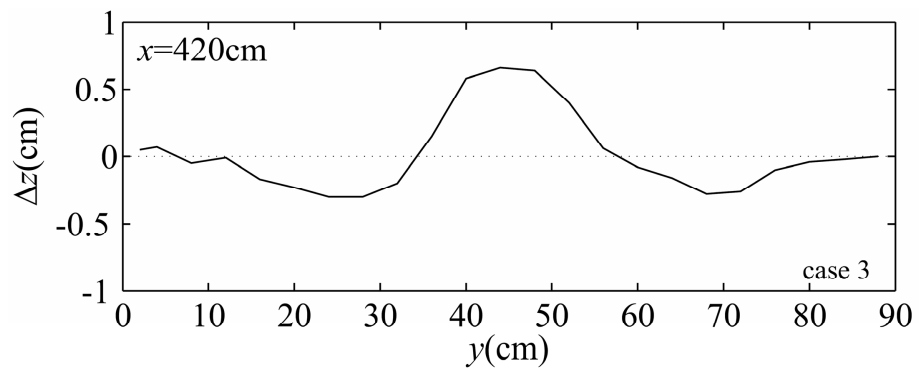

Figure 9. Bottom topography change in the $y$-direction at $x=420 \mathrm{~cm}$

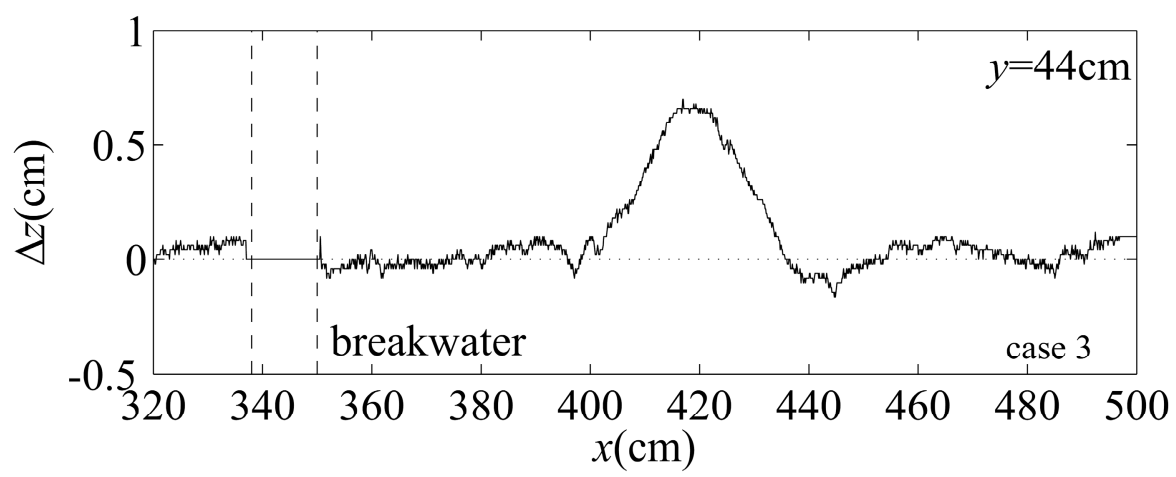

Figure 10. Bottom topography change in the $x$-direction at $y=44 \mathrm{~cm}$

\begin{tabular}{|c|c|c|c|c|}
\hline \multicolumn{4}{|c|}{ Table 1. Budget of volume on topography change } \\
\hline \multicolumn{2}{|c|}{ region } & & volume $\left(\mathrm{cm}^{3}\right)$ & ratio \\
\hline 1 & harbor entrance & erosion & -150 & 1 \\
\hline \multirow{2}{*}{2} & \multirow{2}{*}{ harbor inside } & erosion & -830 & 6 \\
\cline { 3 - 5 } & & deposition & +450 & 3 \\
\hline
\end{tabular}

conspicuous phenomenon, its eroded volume of $150 \mathrm{~cm}^{3}$ accounts for only $15 \%(1 / 7)$ in total erosion compared with that inside harbor of $830 \mathrm{~cm}^{3}$. It should be noted that erosion inside the harbor is the most significant with the respect to the volume. The volume of deposition accounts for about a half of that of the erosion. When the total volume of the sand is considered, about $500 \mathrm{~cm}^{3}$ of sand is missing. It was transported offshore. That is caused by the intense flow through the harbor entrance and the flow of the vortex in the middle of harbor. 

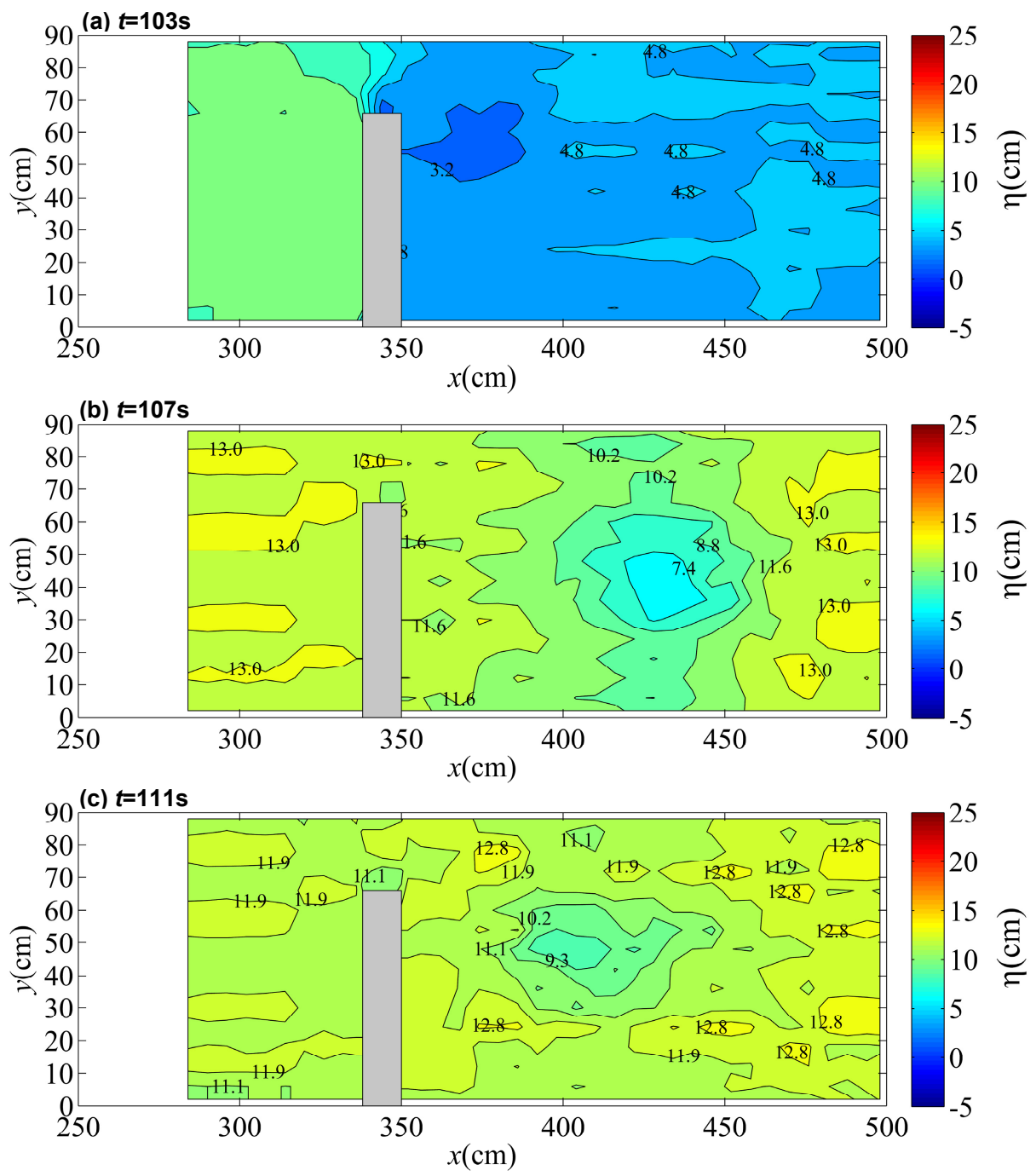

Figure 11. Water surface elevation measured on rigid bed with flatbed

\section{Velocity field}

Figure. 11 shows the contours of free surface displacement on the rigid bed at three stages of tsunami action on the harbor. Fig.11 (a) $t=103$ s shows the water surface level at the time when the tsunami reached the breakwater. The tsunami stagnated in front of the breakwater and the difference of the water depth at the harbor entrance started increasing. A concave contour of the water surface level behind the breakwater shows the separated vortex moving into the harbor. The difference of water depth produced the current with a high velocity which exceeded $100 \mathrm{~cm} / \mathrm{s}$ through the harbor entrance and generates the vortex inside the harbor. Fig.11 (b) $t=107 \mathrm{~s}$ shows the surface water level when the vortex was fully developed in the center of the harbor. Fig. 11 (c) $t=111 \mathrm{~s}$ shows water surface level when the tsunami started retreating. The surface water level inside the harbor was higher than that of outside the harbor, but the vortex remained as showing the a concave water surface level

Figure.12 shows the velocity fields at the corresponding times of the free surface displacement of Fig.11. A clear relationship between the distributions of free surface displacement and the velocity field is observed on the vortex. At the breakwater head the reverse flow due to the vortex is also confirmed although the special solution $(\Delta x=\Delta y=6 \mathrm{~cm})$ of the velocity measurement is not enough for the size of the 

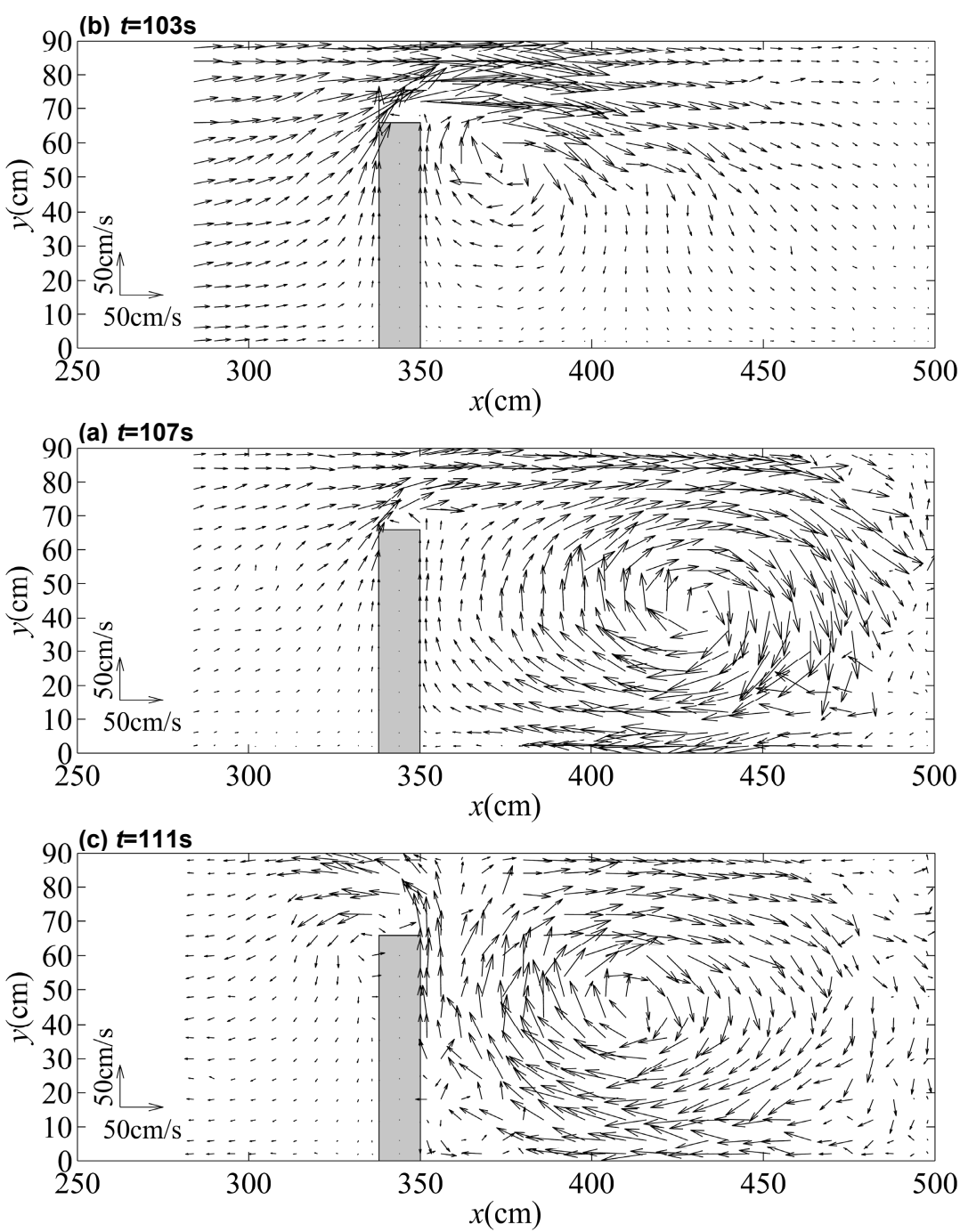

Figure 12. Velocity field showing vortex inside harbor on rigid bed measured at $3.5 \mathrm{~cm}$ above flatbed

vortex in Figures.12 (a). Besides the vortex, three dead water regions at as many corners inside the harbor were clearly observed in Figures.12 (b) and (c).

Since the harbor model of the present experiment is rectangle with two different lengths; one is $90 \mathrm{~cm}$ long and the other $150 \mathrm{~cm}$ long, the size of vortex is more affected by the shorter side of the rectangle harbor than the longer one. The vortex size or diameter depends on the current magnitude and the space of harbor. Yoshii et al. (2010) showed the current inside the model harbor with a more general shape. The dead water regions extended more to two corners in the harbor.

Although the present experiments cannot provide any data, there is an additional possibility of sediment transport due to the vortex. It is well known that there is a viscous boundary layer due to a rotational flow on a flat bed called the Ekman layer (Andersen et al., 2003). The inward flow is induced in this layer; therefore the sediment transport to the center of the vortex is likely to be available because the concentration of the suspended load is the highest near the bed. Kihara and Matsuyama (2010a) showed the effect of the inward flow on the bottom topography change using the three-dimensional hydrostatic numerical model. 


\section{External force on sediment transport}

Here the relationship between the topography change and the Shield number as an external forces is discussed. The Shield number $\Psi$ is given by Eq.(1).

$$
\Psi=\frac{\tau}{\rho g s d}=\frac{u_{*}}{g s d}
$$

where, $\tau$ : the shear stress, $s=\rho_{\mathrm{s}} / \rho-1$ : the specific density of sand in the fluid, $\rho_{\mathrm{s}}$ : the density of sand, $\rho$ : the density of fluid, $g$ : the acceleration due to the gravity, and $d$ : sand diameter. The friction velocity $u *$ in Eq.(1) is obtained applying the logarithmic velocity-distribution expressed by Eq.(2).

$$
\frac{u}{u_{*}}=\frac{1}{\kappa} \ln \left(\frac{z}{k_{s} / 30}\right)
$$

where $\kappa=0.4$ (Karman's constant), $k_{s}$ : the roughness height. In the experiment, the velocity was measured at $3.5 \mathrm{~cm}$ above the bed, therefore $z=3.5 \mathrm{~cm}$. The velocity in the present case is given by the absolute value of the horizontal components of $u$ and $v$.

Figure.13 shows the distribution of the maximum Shield number $\Psi_{\max }$ during a single tsunami train. The maximum value of the Shield number in space is about 2.7 which is a rather large number for the laboratory test. It is obtained at the location of $(x, y)=(400,72)$ in a channel from the harbor entrance directing into the harbor. The maximum value of the Shields number $\Psi_{\max }=2.7$ is a rather big number in the laboratory experiments. By comparing this distribution with the topography change as shown in Fig.8, Fig.13 does not correspond to that of the topography change.

Figure.14 shows the distribution of the time averaged Shield number $\Psi_{\mathrm{m}}$. The time averaged value was obtained from $t=100 \mathrm{~s}$ through $t=140 \mathrm{~s}$. This range of the time is a single tsunami train as the time history of horizontal component of the velocity shows in Fig. 4(b). The distribution of the time-averaged Shields number corresponds to the bottom topography change as shown in Fig.8.

The present experiment has showed that the suspend load due the vortex plays a dominant role in the topography change inside the harbor due to tsunami. Here applicability of the present experimental result will be discussed focusing on the classification of sand transport, that is, which is predominant, the bed load or the suspended load. According to the magnitude of the Rouse number, which is defined as the ratio of the friction velocity to the fall velocity of the sand, the sediment transport is classified into the bed load and the suspended load as follows:

$$
\begin{array}{ll}
\text { Bed load is predominant: } & \frac{u_{*}}{w_{s}}<1.1 \\
\text { Suspended load } \quad \text { is } & 1.7<\frac{u_{*}}{w_{s}}
\end{array}
$$

The relationship of the fall velocity $w_{s}$ and the sand diameter, $d$ is given by the Rubey's formula and Soulsby's formula. They are given by Eq.(3) and Eq.(4), respectively.

$$
\begin{gathered}
w_{s}=\sqrt{\frac{2}{3} s g d+\frac{36 v^{2}}{d^{2}}}-\frac{6 v}{d} \\
w_{s}=\frac{v}{d}\left\{\left[10.36^{2}+1.049\left(\frac{g(s-1)}{v^{2}}\right)^{1 / 3} d\right]^{1 / 2}-10.36\right\}
\end{gathered}
$$




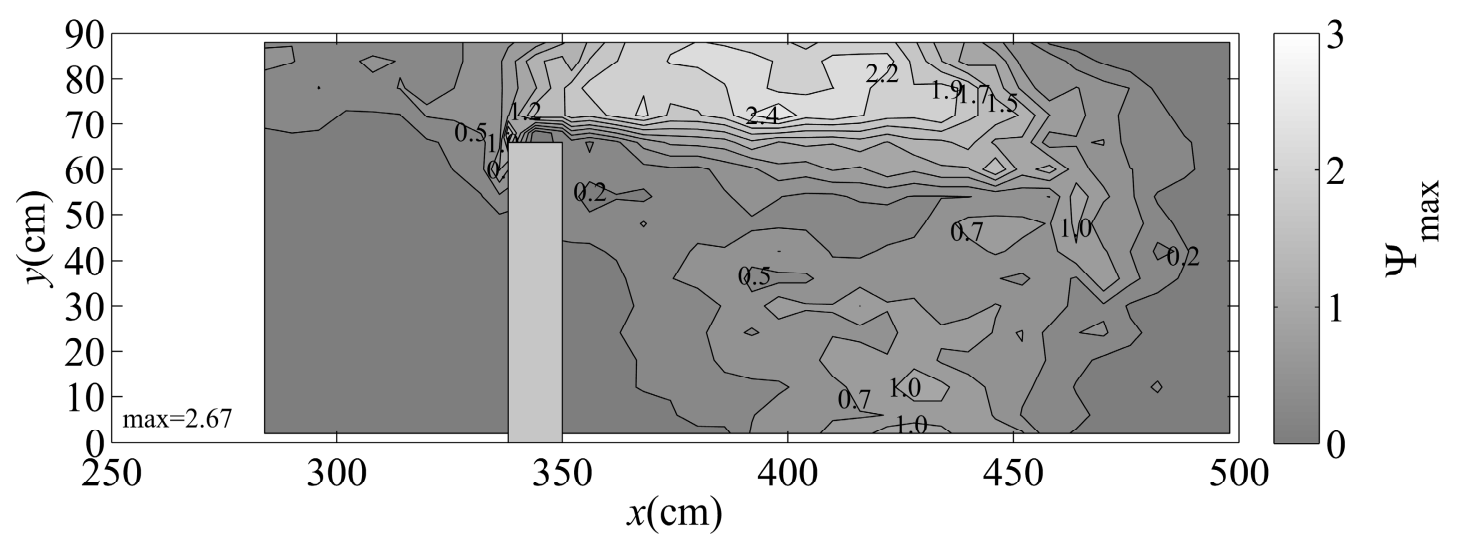

Figure 13. Spatial distribution of maximum Shields number (maximum value of the maximum Shield number $\Psi_{\max }$ is 2.67 )

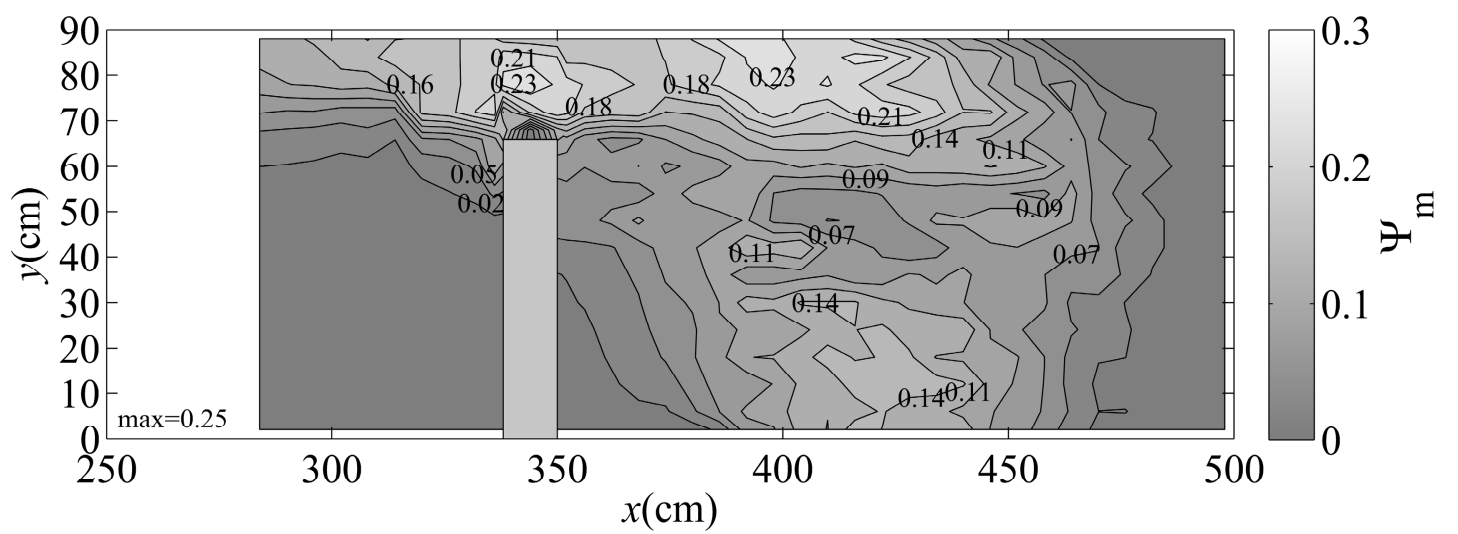

Figure 14. Spatial distribution of time averaged Shields number (maximum value of time averaged Shield number $\Psi_{\mathrm{m}}$ is $\mathbf{0 . 2 5}$ )

where $v$ : the coefficient of kinematic viscosity.

The relationship between the fall velocity of the sand and grain diameter changes drastically from the fine sand to the coarse sand as shown in Fig.15. When the diameter of the sand is less than $0.2 \mathrm{~mm}$, the fall velocity is proportional to the square of the diameter. When it is greater than about $1 \mathrm{~cm}$, the fall velocity is proportional to the square root of the diameter. Experiments are usually carried out according to the Froude law. The scale of velocity is proportional to the square root of the scale of length. The relationship between the fall velocity and the sand diameter of coarse sand satisfies the Froude law. However, the fine sand gives the relatively smaller fall velocity in the experiments. It means that the Rouse number of the experiments becomes large. The experiments on sand movements give us the larger Rouse number while the Shields number remains small in the experiments.

Table. 2 shows the comparison of Shields number and Rouse of the present experiment and the field result by Fujita et al. (2010). Fujita et al. (2010) simulated the topography change in Hachinohe port in Japan due to the 1960 Chilean tsunami. The sand diameter is $0.26 \mathrm{~mm}$ and its fall velocity $3.5 \mathrm{~cm} / \mathrm{s}$. The maximum Shield's number was 7.8 and the time and special averaged Shield number is 1.14 and the Rouse number 3.9, while the present experiment gives them 0.07 and 4.2. There is a big gap of the Shield number between the field and the calculation but that of the Rouse number is quite small. One index is selected that is both time and spatial averaged value. It means that the suspend load is predominant in both the present experiment and the field phenomena. Since the Shield number in the experiment is small, the amount of suspended load in the experiment is also smaller compared with that of the field. The phenomenon of the suspended load itself was reproduced well in the experiment. 


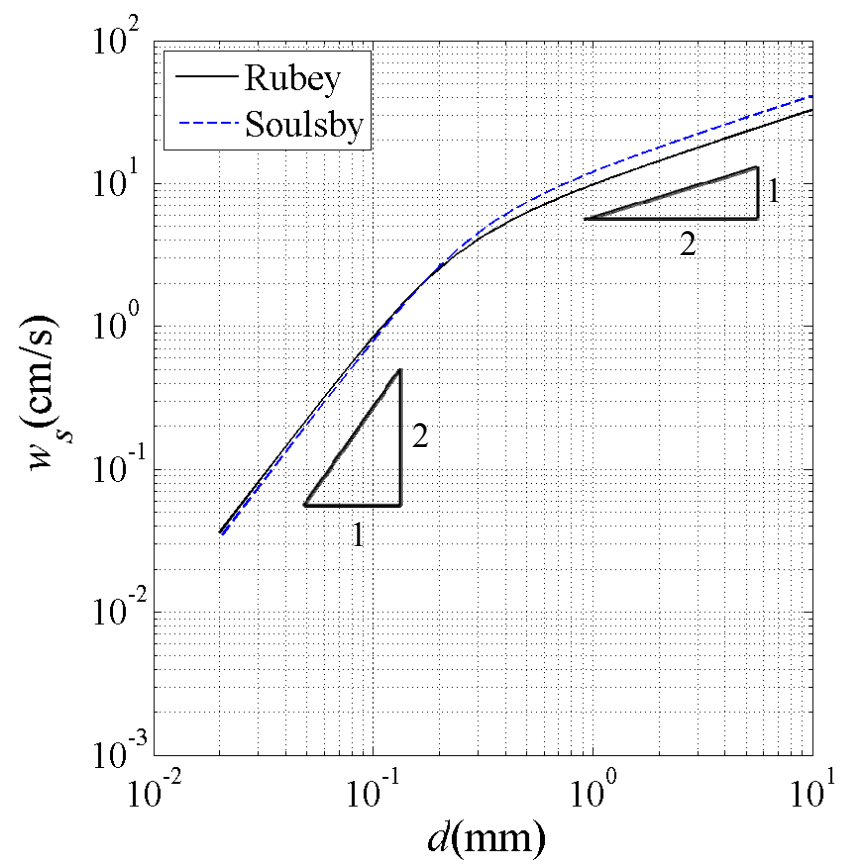

Figure 15. Relationship between fall velocity and sand diameter

\begin{tabular}{|c|c|c|c|c|c|c|}
\hline \multicolumn{7}{|c|}{ Table 2. Shields number and Rouse number of experiment and field } \\
\hline & $\begin{array}{c}d_{50} \\
(\mathrm{~mm})\end{array}$ & $\begin{array}{c}w_{s} \\
(\mathrm{~cm} / \mathrm{s})\end{array}$ & $\begin{array}{c}\text { s.a. } \\
\Psi_{\max }\end{array}$ & $\begin{array}{c}\text { s.t.a. } \\
\Psi\end{array}$ & $\begin{array}{c}\text { s.t.a. } \\
u *(\mathrm{~cm} / \mathrm{s})\end{array}$ & $\begin{array}{c}\text { s.t.a. } \\
u * / w_{\mathrm{s}}\end{array}$ \\
\hline present experiment & 0.08 & 0.55 & 0.56 & 0.07 & 2.3 & 4.2 \\
\hline $\begin{array}{c}\text { Field application } \\
\text { (Fujita et al. 2010) }\end{array}$ & 0.26 & 3.5 & 7.84 & 1.14 & 13.7 & 3.9 \\
\hline \\
s.a: spatial averaging, s.t.a.: spatial and time averaging \\
\hline
\end{tabular}

\section{CONCLUSIONS}

The bed topography change due to tsunami was investigated experimentally. The accumulation was observed near the center of the harbor where the vortex stays with high concentration of the suspended sand. In the dead water regions at three corners of the rectangular harbor model, accumulation was also observed although the amount of deposition was small.

The process of bed topography change in a harbor due to tsunami is summarized as follows:

1. A vortex at breakwater head is initiated and causes the sediment transport resulting in the local scour.

2. Second vortex separates and moves into the harbor producing the suspended load. While it grows in the middle of the harbor, the sand transport due to the advection and the diffusion causes the deposition near the vortex center.

3. The area is eroded in the surrounding of the vortex center.

4. There is another mechanism of the sediment transport: it is due to the advection of sediment which is induced by the inward flow in the Ekman layer near sand bed.

5. The accumulation with a conical form features the bottom topography change due to the tsunami.

Due to the relationship of the fall velocity and the sand diameter, the Rouse number of the present experiment is greater than unity and almost equivalent to that of the field. It means the suspended load is 
significant in the sand transport and the present experiment reproduced the field phenomenon although the amount of picked-up volume was small.

The dataset of topography, free surface displacement and velocity filed and time series of suspended sediment concentration are available to verify a numerical simulation model for estimate sand bed change due to tsunami.

\section{REFEERNCES}

Andersen, A., B. Lautrup, and T. Bohr. 2003. An averaged method for nonlinear laminar Ekman layers, Journal of Fluid Mechanics, 487, 81-90.

Fujii, N., M. Ohmori, M. Takao, S. Kanayama, and H. Ohtani. 1993. On the Deformation of the Sea Bottom Topography due to Tsunami, Proceedings of Coastal Engineering, JSCE, 45, 376-380(in Japanese).

Fujita, N., K. Inagaki, N. Fujii, M. Takao, and T. Kaneto. 2010. Study on field application of estimation model for topography change due to tsunamis, Annual Journal of Civil Engineering I the Ocean, JSCE, 26, 213-218(in Japanese).

Mizuguchi, M. 1991. Method of resolving incident and reflected waves in shallow water, Proceedings of Coastal Engineering, JSCE, 38, 31-35(in Japanese).

Kihara, N., and M. Matsuyama. 2010a. Three-dimensional hydrostatic numerical simulations on tsunamiinduced sediment transport in a model harbor, Abstracts of the 3rd International Tsunami Field Symposium, 31-32.

Kihara, N., and M. Matsuyama. 2010b. Numerical simulations of sediment transport induced by the 2004 Indian Ocean tsunami near the Kirinda port in Sri-Lanka Proceedings of the 30th International Conference on Coastal Engineering. (in press)

Rubey, W.W. 1933. Settling velocities of gravels, sand and silt particles, American Journal of Science, 25, 325-338.

Soulsby, R. 1998. Dynamics of marine sands, Thomas Telford, 270p.

Takahashi, T., N. Shuto, F. Imamura, and D. Asai. 2000. Modelling sediment transport due to tsunamis with exchange rate between bed load layer and suspended load layer, Proceedings of International Conference on Coastal Engineering, 2, ASCE, 1508-1519.

Yoshii, T., M. Ikeno, and M. Matsuyama. 2009. Experimental study of sediment transport caused by tsunami, Proceedings of Coastal Dynamics 2009, Paper No. 32.

Yoshii, T., M. Ikeno, M. Matsuyama, and N. Fujii. 2010. Pick-up rate of suspended sand due to tsunami, Proceedings of the 30th International Conference on Coastal Engineering. (in press) 